\title{
O problema da verdade e a educação
}

Renato José de Oliveira

Palavras-chave: verdade;

ética; educador.

\footnotetext{
1 As datas indicadas entre parênteses são marcos aproximados. No fragmento II do célebre poema Sobre a Natureza, ao ser recebido na clara e acolhedora morada da deusa, Parmênides é advertido sobre a existência de duas vias para o conhecimento: "a primeira, a saber, que o ser é, e queéimpossível para ele não ser, é a via na qual se deve confiar, pois segue a Verdade" (apud Brun, 1988, p. 62).
}

\section{Resumo}

Tendo em vista que, desde a Grécia antiga, a verdade tem sido considerada um ideal para o conhecimento humano, discute alguns aspectos das críticas feitas por filósofos como Chaim Perelman e por alguns cientistas contemporâneos. A verdade eterna, como base para o conhecimento e para os julgamentos morais, cede lugar à noção de verdade provisória, construída pelos homens no curso de sua existência social. Em conseqüência, as relações éticas e pessoais são debatidas com vistas a levantar questões polêmicas e interessantes para os professores e todos os que lidam com crianças e com jovens em geral.

\section{Conhecimento e verdade}

Uma temática central da filosofia tem sido o estatuto do conceito de verdade. Empregando uma metáfora bem conhecida, desde Parmênides de Eléia (515-450 a.C.), a Verdade com V maiúsculo vem sendo associada à luz que ilumina as decisões sábias a tomar, as medidas corretas a executar, os melhores ensinamentos a ministrar. ${ }^{1} \mathrm{Em}$ contrapartida, a opinião, o julgamento plausível e a escolha razoável foram colocados no limbo da obscuridade porque não proporcionam certeza de nada, segurança alguma. Conhecer, portanto, significa ter acesso ao que é evidente e se impõe a todas as criaturas dotadas de razão.

Perelman (1997, p. 361) chama a atenção para o fato de que o critério da evidência tem por finalidade descrever o real tal como ele objetivamente seria. A descrição deve, pois, coincidir com a natureza do objeto, afastando do pensamento tudo o que ele não pode ser. Em vista disso,
A evidência não pode sofrer nenhuma variação, nem no espaço nem no tempo, e não pode depender das características individuais da mente. Será a mesma para cada qual, seja qual for seu temperamento ou sua formação, sua idade ou sua pátria; todos esses elementos subjetivos e variáveis, que diferenciam os homens, constituem obstáculos para o exercício dessa faculdade invariável e presente em cada ser humano normalmente constituído, que é a razão. O uso correto da razão será, pois, precedido de uma ascese, de uma purificação do sujeito, da eliminação de tudo que poderia formar obstáculo para a percepção de idéias evidentes.

Nos dias de hoje, porém, a ascese racional, que visa constituir um sujeito cognoscente desencarnado, é posta em xeque nos mais diferentes campos do saber. A História das ciências, por exemplo, tem mostrado que a revisão do que se tinha por evidência é necessária ao avanço do conhecimento. Tomemos o caso da física newtoniana. Construída sobre bases 
deterministas e sobre o pressuposto de que o experimento revela a verdadeira natureza ou natureza intrínseca do objeto investigado, cedeu lugar ao indeterminismo e ao interacionismo da física quântica. Explicando melhor: não é possível determinar para um objeto microfísico (um elétron, por exemplo) sua posição espacial e sua velocidade simultaneamente, como se pode fazer para uma pedra ou qualquer outro corpo macroscópico em movimento. O princípio da incerteza, formulado por Heinsenberg, indica que quanto mais se busca determinar com precisão um desses dois parâmetros, a determinação do outro se torna mais inviável. Isso porque o próprio experimento é uma interação entre o objeto estudado e os instrumentos de medida utilizados na investigação. O experimento não descreve, por assim dizer, como o objeto é em si mesmo, não anuncia suas propriedades (corpuscular e ondulatória, no caso do elétron), mas aponta como este se comporta perante determinado procedimento investigativo.

Do ponto de vista epistemológico, a revolução quântica expressa um movimento renovador do pensamento que, não sem dificuldades, se liberta dos moldes estreitos estabelecidos pela crença nas evidências para atingir outros patamares. Como frisa Bohr (1995, p. 31):

Quão radical foi a mudança promovida por esse avanço da física atômica em nossa atitude perante a descrição da natureza talvez possa ser mais claramente ilustrado pelo fato de que até o princípio da causalidade, antes considerado o fundamento incontestável de toda interpretação dos fenômenos naturais, revelou-se um referencial estreito demais para abarcar as regularidades singulares que regem os processos atômicos individuais. Sem dúvida, todos hão de compreender que os físicos precisaram de razões muito convincentes para renunciar ao próprio ideal de causalidade; mas, no estudo dos fenômenos atômicos, foi-nos repetidamente ensinado que questões que se acreditava terem recebido suas respostas finais há muito tempo haviam reservado para nós as mais inesperadas surpresas.

Os problemas relativos aos métodos investigativos e à racionalidade experimental, ao que é tido por relevante na pesquisa científica e do que é considerado irrelevante, à interferência do observador sobre o objeto de estudo são vistos por Stengers como desafios ao ideal clássico de conhecimento. Dentre os muitos exemplos dados pela autora, o referente aos babuínos (Stengers, 1989, p. 168-169) é particularmente interessante. Após terem estudado diferentes populações destes animais, diferentes etólogos enunciaram regras de comportamento bastante distintas. Para uns estes primatas comportavamse como gangues, para outros seguiam o modelo do patriarcado, havendo ainda cientistas que defendessem a existência do matriarcado. No calor dos debates, o argumento mais comum era o de que as diferenças observadas não diziam respeito aos babuínos, mas à projeção, em seu comportamento, das próprias visões de mundo dos especialistas. Em dado momento, porém, uma etóloga levantou a hipótese de que talvez nenhum dos pesquisadores estivesse certo ou errado. Na verdade, todos procuravam a regra geral que deveria prescrever o comportamento dos babuínos, deixando de colocar para si próprios a questão: existiria mesmo uma regra geral? Ora, à medida que o objeto constituído por uma dada população de babuínos percebe que está sendo observado, pode perfeitamente inventar uma determinada regra, inventar uma história que não tem obrigação de ser a mesma em outras situações observacionais. Conforme destaca Stengers (1989): "Os babuínos não se interessam pela solução que o babuinólogo descobre, mas é sabido que os animais se interrogam sobre a presença dos etólogos".

Em termos clássicos, lógico-formais, a alternativa proposta pela etóloga causa estranheza, porque fere o princípio de nãocontradição: ou a conclusão X está certa ou está errada. Ela não pode estar certa e errada, não pode ser e não ser ao mesmo tempo. A reação, ou melhor dizendo, a interação entre objeto e sujeito na pesquisa científica é produtora de eventos desconcertantes, mas do ponto de vista da ciência experimental o pesquisador se põe em contato com um universo que lhe é indiferente. Tal indiferença, aliada à crença de que os objetos sempre devem responder do mesmo modo às leis gerais que os governam, cria um divisor de águas arbitrário entre o secundário e o essencial, o detalhe e a propriedade relevante. Em função disso muitos problemas não são colocados porque sequer são pensados como problemas.

Como o conhecimento científico não pode mais sustentar o estatuto de saber verdadeiro, ou seja, aquele que permite dizer de maneira inequívoca o que o objeto é em 
si mesmo, deve assumir outra condição: a de explicar a realidade tanto quanto as circunstâncias histórico-sociais que uma época permite. Não se trata mais de um saber absoluto, fundado sobre a verdade, mas de um saber provisório que responde satisfatoriamente aos principais problemas epistêmicos postos em debate. Mazzotti e Oliveira (2000) denominam este tipo de saber de conhecimento confiável.

Tal noção busca devolver ao conhecimento o caráter de empresa verdadeiramente humana: não é a revelação de uma inteligência, de uma ordem ou de uma vontade transcendentes, mas fruto do pensar e do fazer do homem como ser concreto e participante em um contexto complexo de relações que envolvem tanto a natureza quanto a sociedade. Trata-se de um conhecimento que reabilita a opinião e o julgamento plausível, que passa, então, a possuir estatuto epistemológico. Nas palavras de Perelman (1997, p. 367):

É no esforço, sempre renovado, para fazer que as admitam pelo que consideramos, em cada domínio, como a universalidade dos homens razoáveis que são elaboradas, precisadas e purificadas as verdades, que constituem apenas as nossas opiniões mais seguras e provadas.

\section{Ética e verdade}

À medida que a ética se propõe refletir sobre o que é justo ou injusto, a noção de verdade, como um referente absoluto, também balizou a construção de diferentes sistemas éticos. Buscando normatizar as ações humanas, orientando-as para o justo e afastando-as do injusto, o absoluto ético assumiu as feições de um ser perfeito, modelar, cuja existência é, por si só, a norma das normas. No sistema platônico, a idéia do Bem cumpria esse papel, figurando como autêntico Sol do mundo inteligível que torna bom e justo aquele que for capaz de contemplá-lo. É certo que Platão afirmava ser necessária uma longa preparação (ascese) para lograr esse fim. Quem o alcançasse poderia ser considerado como verdadeiro filósofo e teria, então, qualidades inequívocas para governar com sabedoria e justiça:

Trata-se da conhecida passagem do Livro VI da República, em que Sócrates mostra a Gláucon que os filósofos, diferenciados pelo maior saber, devem assumir as tarefas mais relevante (484 a.D.).

\footnotetext{
- Uma vez que os filósofos são capazes de atingir aquilo que se mantém sempre do mesmo modo, e aqueles que o não são, mas se perdem no que é múltiplo e
}

variável, não são filósofos, qual das duas espécies é que deve ser chefe da cidade?

- Que hei de eu dizer para dar uma resposta adequada?

- Que aquele dentre os dois que parecer capaz de guardar as leis e costumes da cidade, esse mesmo seja nomeado guardião.

- Exactamente - corroborou ele (Platão, 1997, p. 267). ${ }^{2}$

Para os estóicos, a tríade DeusNatureza-Razão, presente em tudo que existe, regularia as ações humanas. Quando o homem se conformasse à condição de ser que encarna harmoniosamente esses três elementos, deixaria de sofrer e encontraria a felicidade. A ordem universal, da qual a razão humana seria parte inalienável, precisaria ser posta em conformidade com a existência individual; portanto, o verdadeiro sábio conseguiria ver as contingências (ser senhor ou escravo, rico ou pobre, famoso ou anônimo) como conseqüências desta ordem maior e não se perturbaria, ficando totalmente indiferente a elas. Quanto mais a razão levasse o homem a se pôr em conformidade com o grande plano universal, modelar e perfeito, mais estaria trabalhando no sentido de torná-lo bom, justo e, conseqüentemente, feliz.

A ética cristã, similar à estóica em certos aspectos, tem como modelo o martírio do enviado, do salvador, do ser divino e perfeito encarnado em homem. Suas palavras devem ser repetidas, divulgadas, e suas ações, imitadas, como no conhecido exemplo de oferecer ao agressor, após o golpe, a outra face. É o próprio Cristo o porta-voz de uma justiça imutável, infinitamente bela e verdadeira, justiça que Pascal tanto gostaria de ver reinar entre os homens para todo o sempre:

O esplendor da verdadeira eqüidade teria conquistado os povos e os legisladores não teriam tomado como modelo - em lugar da justiça imutável - as fantasias e os caprichos dos persas e dos alemães (...).

Três graus de latitude subverteram toda jurisprudência; um meridiano decide qual é a verdade; no curso de alguns anos as leis fundamentais mudam; o direito tem suas épocas (...). Singular justiça esta que tem como fronteira um rio. Verdade deste lado dos Pirineus, erro do outro lado (apud Reale, Antisseri, 1988, p. 523).

Perfeição e Verdade parecem irmanadas e se configuram como antídoto contra todo 
o mal e toda a injustiça. Mas e se o bem e o justo fossem indiscerníveis de seus contrários, como sustentaram os cépticos? Se aquilo que é não valesse mais do que aquilo que não é, conforme afirmava Timón, discípulo de Pirrón de Elis? ${ }^{3}$ Então nos restaria a suspensão dos juízos, ou seja, declarar-nos incapazes de distinguir entre o justo e o injusto e, assim, abstermo-nos de qualquer ação. Ao invés do chão firme proporcionado pelo modelo perfeito a ser imitado, teríamos na nossa frente o pântano das dúvidas gerado pela ausência de qualquer modelo.

Comentando a posição céptica, Perelman (1997, p. 139) frisa com muita propriedade que ela combate o absolutismo com o seu antípoda, o antiabsolutismo exacerbado. O cepticismo constitui-se, assim, puro negativismo que, por não poder dizer o que é a verdade, nada diz sobre o existente. Pirrón, aliás, se caracterizava pela afasia (recusa em se pronunciar), por entender que entre o dito e o não dito não há qualquer diferença. Os cépticos, porém, se esquecem de que o não agir é também uma escolha e, como tal, traz conseqüências para quem a assume: contribuir para a conservação de um dado statu quo. Assim, a ética da não ação leva, por caminhos diferentes, à mesma ataraxia (indiferença ante o mundo) cultivada pelo sábio estóico. Como, então, escapar às duas faces dessa mesma moeda? Como encontrar alternativas?

Uma perspectiva pode ser a de considerar que os fins ou bens morais não são fixos, isto é, não são metas que possam ser estabelecidas a priori e alcançadas mediante um guia infalível, a Verdade absoluta. Também não é possível alimentar infinitas controvérsias sobre o bem e o mal ou então calar-se e deixar que as coisas tomem a conformação que o existente lhes dá. Sob esse ponto de vista, Dewey (1958, p. 176-177) salienta que o mais importante é a ação humana em curso, em processo:

O fim não é jamais um fim de estrada ou um limite a ser atingido, é antes o processo ativo pelo qual se consegue transformar a situação existente. Não a perfeição como um alvo final, mas o processo permanente de aperfeiçoamento, maturação e correção é que é o alvo da vida. A honestidade, a operosidade, a temperança, a justiça, como a saúde, a riqueza e a instrução não são bens a serem possuídos como o seriam se expressassem fins fixos a serem atingidos. São direções de mudança na qualidade da experiência. O crescimento, o desenvolvimento em si mesmo é o único "fim" moral.

O agir ético se constitui, portanto, objeto de exame constante dos elementos que forjam a existência humana e que se modificam no curso dos tempos. Não é possível estabelecer os limites que separam o justo do injusto sem que diferentes concepções sejam confrontadas. O julgamento e as normas resultantes desse embate serão tão mais legítimos quanto mais interlocutores participarem do processo, argumentando em defesa dos seus pontos de vista. A eutanásia é justa? O aborto é crime? Sem dúvida essas questões não podem ser satisfatoriamente respondidas com base no conceito de uma verdade imutável ou deixarem de sê-lo porque é impossível julgá-las. A tarefa, difícil mas realizável, é adotar critérios de justiça e injustiça suscetíveis, como no caso dos conhecimentos confiáveis, à revisão quando esta for uma demanda do processo histórico-social no qual o homem, como espectador e ator, se acha inserido.

\section{Cotidiano e verdade}

As relações pessoais cotidianas, parte significativa da vida, também nos colocam diante do problema da verdade. Será que o amigo que tanto prezamos, o ser amado a quem nos entregamos e todos aqueles com quem mantemos as mais diversas relações falam a verdade ou mentem?

A questão, simples à primeira vista, é, porém, bastante complexa, pois o homem é um ser relacional. Para o indivíduo isolado há uma verdade absoluta com respeito às ações que pratica. Mas para o outro, para aquele a quem a ação é comunicada, a verdade assumirá caráter de algo verossímil ou não.

Os antigos gregos já tinham conhecimento disso, e, assim, desenvolveram a arte retórica como meio de permitir que os homens, baseando-se em critérios de plausibilidade e verossimilhança, se relacionassem no mundo. O exemplo a seguir ilustra bem o que se quer dizer. Suponhamos, afirmava Córax (cerca de 465 a.C.), que dois vizinhos vivem em litígio por diversas razões, sendo que um deles é um homem forte e corpulento e o outro, fraco e franzino. Certo dia este último aparece morto, vítima de uma agressão. Quem
3 Pirrón (cerca de 300 a.C.) é situ-
ado como o fundador da escola
céptica. 
será tomado como o virtual criminoso? O homem forte, naturalmente. Mas este, por sua vez, poderá sustentar que, justamente por todos saberem que ele seria o principal acusado, jamais cometeria o crime. Em princípio, para o homem forte há uma verdade (matou ou não matou seu desafeto), mas as demais pessoas se dividirão quanto ao juízo que farão das versões apresentadas, o que coloca ambas na condição de relatos verossímeis. Em termos penais, é possível realizar uma investigação e reunir elementos que fortaleçam uma das versões e enfraqueçam a outra, o que permitirá a um juiz ou júri decidir sobre a absolvição do réu ou o tipo de condenação cabível. Contudo, a decisão judicial continua assentada sobre o verossímil e somente o réu tem condições de saber se prevaleceu ou não a verdade.

A retórica nos coloca, pois, perante o desafio de construir verdades mediante o falível, mas humano, exercício da palavra e do juízo, ou de permanecer no silêncio das certezas que não podem ser comunicadas. Como bem salienta, Fumaroli (1999, p. 5):

A retórica nasceu, juntamente com a sofística, a filosofia e a ciência, quando a religião deixou de reger exclusivamente a cidade. Uma tal arte pressupõe que o homem, como animal falante e dotado de razão, propõe-se como um enigma ainda mais inesgotável que o mistério dos deuses. Ele desenvolve e aprofunda a resposta de Édipo à Esfinge. Sofistas, filósofos, filósofos da natureza se debruçam sobre esse enigma ou se apóiam nele de modos distintos e freqüentemente opostos. A retórica tira partido dessas investigações divergentes e as faz dialogar em sua reflexão sobre a arte de falar, a qual faz de um enigma uma aposta: a de persuadir.

Acreditar completamente na inocência ou na culpabilidade de alguém, na sua sinceridade ou na sua falsidade, é agarrar-se a um absoluto. E, como nos planos do conhecimento e da ética, também aqui a confiança cega leva a dogmatismos muitas vezes intoleráveis. Persuadir o outro, isto é, fazer com que ele se ponha de acordo conosco quanto ao que dizemos ser verdadeiro é um procedimento legítimo, sobretudo se intimamente sabemos que nosso pronunciamento é verdadeiro. Todavia, ao outro restará sempre uma margem de incerteza, uma região de sombra em que as dúvidas serão nutridas. Isso é humano e condená-lo por exercer a dúvida significa assumir uma postura dogmática.
Perelman (1987, p. 236) assinala que os níveis de adesão de um interlocutor são variáveis porque nenhuma argumentação tem caráter coercivo. Isso vale para todos os campos do existir em que se dá o confronto entre versões mais e menos verossímeis para explicar um determinado fato ou sistema de fatos. Por certo as exigências e o rigor que pedimos quanto à coordenação dos elementos expostos na argumentação cotidiana não é de mesma natureza que aqueles exigidos nos planos científico e ético. De todo modo, argumentar é sempre ter em vista a totalidade de elementos que compõem uma dada situação, já que o homem, em si mesmo, é também uma totalidade:

Aquele que argumenta não se dirige ao que é considerado como faculdades, tais como a razão, as emoções, a vontade. O orador se dirige ao homem pleno, embora, conforme o caso, a argumentação procure efeitos diferentes e utilize, em cada vez, métodos apropriados, tanto ao objeto do discurso quanto ao tipo de auditório sobre o qual quer agir. Assim, um advogado, em uma ação comercial, criminal, política ou de direito comum, de direito privado ou de direito internacional público - e segundo o tipo de tribunal que deve convencer - não utilizará nem o mesmo estilo nem o mesmo tipo de argumentação (Perelman, 1988, p. 26-27).

Em muitas situações, um relato falso é tão bem concatenado que se torna difícil não considerá-lo verdadeiro. Em outras se dá justamente o contrário. Isso faz com que tenhamos, principalmente nos casos em que achamos que o relato é falso, o desejo de arrancar do discursante a verdade a qualquer preço. A confissão surge, então, como um alívio, mas é preciso lembrar que mesmo esta pode não representar a verdade, pois submetido a uma situação de coação ou de grande constrangimento, o interlocutor pode admitir ter feito o que efetivamente não fez.

A compreensão de que no universo das relações pessoais é também o verossímil e não o verdadeiro que rege o estarno-mundo pode contribuir para tornar as pessoas menos violentas, menos agressivas, menos intolerantes umas com as outras. Pode representar um avanço no que concerne a não medir o outro por nossos próprios parâmetros, a não desqualificálo, porque pensa e age diferentemente do que entendemos por certo e por errado. Afinal, triste e monótono seria o mundo em que o outro fosse tão-somente o espelho do que somos. 


\section{Desafios para o educador contemporâneo}

Diante do que foi discutido acerca do conhecimento, da ética e das relações pessoais, os desafios postos para o educador parecem imensos. Se o chão firme da verdade absoluta treme, como assentar os alicerces que permitirão formar o educando? Como construir uma escola sobre bases tão frágeis?

Trabalhar com a noção de conhecimento confiável, confrontando diferentes modelos explicativos, pode contribuir para tornar o professor mais aberto e receptivo à pluralidade de saberes e, inclusive, levá-lo a compreender melhor por que muitos alunos têm grandes dificuldades em aprender o que parece simples e óbvio. Uma dificuldade que sempre se apresenta para os estudantes é a distinção entre modelo e realidade. Freqüentemente se acredita que esta é descrita com fidedignidade por aquele, não havendo diferença entre o que é pensado e o próprio existente. Deste modo, estruturas como a do DNA, por exemplo, não são vistas como construções conceituais, mas como espelhos fiéis da substância. Aquilo que se apresenta como modelo, como representação, é tomado pelo próprio objeto, conforme bem assinala Mortimer (1998, p. 108):

Continuamos a ensinar os modelos como se fossem a realidade. Escrevemos equações químicas nos quadros-negros como se fossem as próprias reações e não suas representações; desenhamos orbitais moleculares como se fossem reais. E nos escondemos atrás da linguagem científica, neutra e a-sujeitada, fria e atemporal, pretensamente universal, para ensinarmos uma ciência clássica, na maioria dos casos já superada historicamente, como a verdade imutável. Não damos voz a nossos alunos, não escutamos como descrevem suas experiências e seu mundo em linguagem cotidiana.

Tal identificação sumária entre a representação científica do objeto de conhecimento e o objeto em si mesmo não se constitui, do ponto de vista do resultado esperado nas avaliações escolares, nenhum grande problema. As questões e os exercícios propostos levam muito mais em conta a capacidade de o aluno operar com os conceitos do que o modo como ele os compreende. Assim, se as equações químicas forem corretamente balanceadas no papel ou se os problemas envolvendo planos inclinados forem adequadamente resolvidos, pouco importa saber se o estudante domina os porquês da aplicação. O contexto de produção do conhecimento, sua história repleta de avanços e recuos, as polêmicas envolvendo diferentes concepções da natureza e diferentes formas de raciocínio não têm lugar nas provas escolares. Contudo, é preciso perguntar se o que permanece na mente do aluno, após a realização dos exames, é uma compreensão que lhe permite problematizar o processo de construção do pensamento científico e suas implicações para a vida cidadã ou somente um conjunto de estratégias empregadas para obter graus de aprovação.

Do ponto de vista de uma pedagogia não comprometida com a memorização e com o adestramento, a relevância maior de ensinar não está no resultado final expresso por números em um boletim escolar, mas em estimular a capacidade de reflexão do sujeito que se propõe conhecer o mundo. Naturalmente, quando isso ocorre, o pensamento crítico também se desenvolve.

À medida que o diálogo (que em grego significa contato entre razões) se sobrepuser às práticas tradicionais de transmissãorecepção de conhecimentos, as aulas se tornarão mais dinâmicas e os programas escolares menos distantes da realidade imediata do aluno. Sem dúvida, quando busca desenvolver novas metodologias, o professor tem diante de si alguns obstáculos um deles é vencer a resistência e o desconforto do estudante, muitas vezes habituado a lidar com tarefas escolares que, embora possam ser consideradas maçantes, são ao menos familiares. Quando o docente introduz em suas aulas estratégias como a problematização de conceitos, por exemplo, pode ser visto com desconfiança e também ser questionado em relação aos conteúdos que ensina. Todavia, uma vez superada a estranheza inicial, abrem-se perspectivas para que o aluno supere a passividade e o comodismo de apenas memorizar e repetir o que lhe é ensinado. Seu raciocínio se torna, gradativamente, mais e mais exigente e, deste modo, passa a não temer as dificuldades. Os modelos, que são esquemas abstratos essenciais à compreensão da ciência, passam a ser reconhecidos como construções transitórias, mais ou menos confiáveis conforme as exigências postas pelas comunidades científicas em determinado tempo histórico. 
Quanto à formação do caráter do educando - tarefa que não compete apenas ao professor, mas que também lhe cabe-, é preciso exercer a crítica em relação aos modelos de virtude, sejam eles formas de comportamento consagradas, pessoas ou instituições. Em termos pedagógicos, trata-se de pôr em discussão as situações que envolvem diferentes juízos de valor, evitando as soluções mais fáceis e familiares, ou seja, ditar o que é válido e o que não é. Ao agir deste modo, afastando das crianças e dos jovens aquilo que não serve (os antimodelos) e alegando simplesmente que "a escola não é lugar para essas coisas", o professor empobrece as relações educativas. Isso porque são os seus juízos (éticos, estéticos, religiosos, etc.) que se impõem como verdades absolutas. Ao não converter as atitudes inoportunas em objeto de conversação, ao não expor as razões pelas quais as considera inadequadas, ao deixar de pedir que o aluno exponha suas próprias razões, o professor se torna autoritário e, assim agindo, acaba por estimular aquilo que busca combater. Conforme salienta Obiols (1997, p. 20), é preciso admitir que:

[...] nas sociedades modernas a pluralidade e a tolerância permitem a convivência de diversos ideais e doutrinas morais e que o desenvolvimento moral dos indivíduos consiste em um progresso no sentido da racionalidade, isto é, da aceitação ou da não aceitação dos códigos sociais por razões e não por mera disciplina face às convenções postas pela tradição ou por temor às pressões do grupo.

Tal racionalidade é de tipo retórico, ou seja, está balizada pelos critérios de plausibilidade e de verossimilhança. Pede e oferece razões, justificativas que não se pautam por princípios como o de praticar o "dever pelo dever" ou o de "obedecer porque a autoridade manda". No primeiro caso, o princípio é tão-somente um imperativo formal que não contribui para o desenvolvimento de uma racionalidade aberta, mas, pelo contrário, limita o pensamento crítico. No segundo, enseja a cristalização de um conformismo pragmático, que mede o valor da ação (obediência) em função das conseqüências que poderão advir (punições), caso ela não seja praticada.

É importante frisar, entretanto, que a racionalidade retórica não se coaduna com a permissividade, ou seja, com a admissão tácita de que o aluno pode fazer o que quiser na hora em que bem entender, pois possui razões individuais para isso. Os processos dialógicos são caminhos por meio dos quais os interlocutores buscam as melhores razões, reconhecendo os próprios erros quando os argumentos que os sustentam perdem consistência. Naturalmente não é fácil para ninguém admitir que a razão do outro é melhor; todavia, quando o diálogo é praticado em um contexto de mútua confiança, converte-se em interação que permite o desarmamento dos espíritos e por isso representa um salto de qualidade em relação à imposição sumária das normas ou à aceitação delas por mera conveniência.

Outro aspecto a ressaltar é que o cultivo de certos estereótipos, como o do "bom aluno" que se destaca pela dedicação ao estudo e pela disciplina, representa, também, uma postura não problematizadora. Por que o aluno não estudioso, não aplicado, por vezes até indisciplinado, deve ser taxado de mau? Por que aquele que às vezes mente ou omite coisas deve ser considerado falso? No primeiro caso, a certeza de que a escola e os métodos de ensino desenvolvidos representam o certo, o justo e o verdadeiro em termos de educabilidade leva o professor a considerar o aluno inadaptado como possuidor de má índole. Assim, este não estuda por ser preguiçoso, não se aplica por ser vadio, age de modo indisciplinado por ser rebelde. Entretanto, o "mau" aluno pode apenas estar se comportando de determinada maneira porque para ele, em função de sua história de vida, aquele modelo de escola significa muito pouco.

No que tange à sinceridade e à falsidade, cabe retomar o que foi comentado no tópico anterior. Para quem ouve um relato, este é sempre verossímil, sendo a credibilidade absoluta um dogma. Rotular um aluno de falso ou mentiroso é considerar que ele sempre mente, condição difícil de admitir para qualquer ser humano. Já Kant dizia que em um mundo constituído somente por mentirosos, a convivência humana seria impossível. É claro que para este filósofo tal conclusão serviu de situação limite para estabelecer o imperativo ético de nunca mentir, condição igualmente dificílima de ser admitida no universo das relações pessoais. Em vista disso, sinceridade e falsidade não podem ser vistas como absolutos, como atributos inalienáveis da pessoa humana; ao contrário, devem ser encaradas como caracteres indissociáveis do contexto relacional em que se manifestam. 
Educar um indivíduo, seja na escola ou fora dela, é tarefa que exige o constante repensar das próprias razões e a abertura para o exame das razões do outro. Não se trata de defender o relativismo sem medidas que declara a equivalência de todas as razões; trata-se de apostar no pluralismo que pede o debate, o confronto, a polêmica, para com eles construir o difícil (mas irrecusável) caminho das escolhas e das decisões.

\section{Referências bibliográficas}

BOHR, Niels. Física atômica e conhecimento humano. Rio de Janeiro: Contraponto, 1995.

BRUN, Jean. Os pré-socráticos. Lisboa: Edições Setenta, 1988.

DEWEY, John. A filosofia em reconstrução. São Paulo: Companhia Editora Nacional, 1958.

FUMAROLI, Marc. Préface. In: FUMAROLI, Marc (Org.). Histoire de la Rhétorique dans l'Europe Moderne (1450-1950). Paris: Presse Universitaires de France, 1999. p.1-16.

MAZZOTTI, Tarso Bonilha; OLIVEIRA, Renato José de. O que você precisa saber em ciência(s) da educação. Rio de Janeiro: DP\&A, 2000.

MORTIMER, Eduardo Fleury. Sobre chamas e cristais: a linguagem cotidiana, a linguagem científica e o ensino de ciências. In: CHASSOT, Attico Ignácio; OLIVEIRA, Renato José de (Org.). Ciência, ética e cultura na educação. São Leopoldo: Unisinos, 1998. p. 99118.

OBIOLS, Guillermo. Enfoques, inserción curricular y metodología para la formación ética y ciudadana. In: DALLERA, Osvaldo et al. La formación ética y ciudadana en la educación general básica. Buenos Aires: Novedades Educativas, 1997. p. 11-28.

PERELMAN, Chaim. Argumentação. Enciclopédia Einaudi. Lisboa: Imprensa NacionalCasa da Moeda, 1987. v. XI, p. 234-265.

. L’empire rhétorique. Paris: J. Vrin, 1988.

. Retóricas. São Paulo: Martins Fontes, 1997.

PLATÃO. A república. 8. ed. Lisboa: Fundação Calouste-Gulbenkian, 1997.

REALE, Giovanni; ANTISSERI, Dario. Historia del pensamento filosófico y científico. Barcelona: Herder, 1988. v. II.

STENGERS, Isabelle. Quem tem medo da ciência? Rio de Janeiro: Siciliano, 1989.

Renato José de Oliveira, doutor em Educação pela Pontifícia Universidade Católica do Rio de Janeiro (PUC-RJ), é professor adjunto do Departamento de Fundamentos da Educação, coordenador do Programa de Pós-Graduação em Educação e vice-diretor da Faculdade de Educação dessa Universidade.

rj-oliveira1958@uol.com.br 


\section{Abstract The problem of truth and education}

Taking into account that, since ancient Greece, truth has been considered an ideal to human knowledge, this paper discusses some aspects of the critical approaches conducted by philosophers like Chaim Perelman and also by some contemporary scientists. The Eternal truth, as basis to knowledge and moral judgments, is replaced by the concept of provisional truth, which is built by mankind in the course of its social existence. Therefore, ethical and personal relationships are debated aiming at pointing out interesting and polemical issues for teachers and all those who deal with children and young people in general.

Keywords: truth; argument; education.

Recebido em 25 de fevereiro de 2005.

Aprovado em 26 de agosto de 2005. 